\title{
The Burnout Level of Call Center Agents in Metro Manila, Philippines
}

\author{
Agnes F. Montalbo \\ Rizal Technological University, Philippines \\ agnesmontalbo@gmail.com
}

Keywords: burnout, call center, MBI-GS, well-being, mental health

\begin{abstract}
The aim of this study was to measure the exhaustion, cynicism and professional efficacy that would determine an individual's level of burnout. A convenient sample of employees $(\mathrm{N}=747)$ was obtained from different call centers in Metro Manila. The results indicated a high level of exhaustion for the age group of 18-29 years old and for the female respondents. More than half of the respondents were high in cynicism and those who reported a low professional efficacy were mostly females. Age showed a significant relationship with exhaustion and cynicism while tenure at present job showed a significant relationship with professional efficacy. Results implied that working in a call center may lead to employee burnout especially for females and those who are new in their job.
\end{abstract}

\section{Introduction}

Call center agents comprises the largest BPO (Business Process Outsourcing) workers in country today. The BPO sector is a contemporary work setting in the Philippines, with a large and relatively young workforce. By 2016, the call center industry forecasts $\$ 25$ billion in revenues and 1.3 million employees [1]. The work of a customer service representative is seen as one of the ten most stressful jobs in the current world economy [2, 3,4]. There is a concern that the demands of the work environment in call center may contribute to stress levels and psychological vulnerability among employees. Various studies conducted by researchers on the call center work environment indicate that many different variables inherent to the nature of call center work and call center work environments have been linked to the development of burnout [5].

Burnout is mostly talked about in Western researches and is related to employee turnover and others. There is a high turnover rates in the Philippine call center with sources as physical and psychological impact of work schedule, lack of social support and social isolation [6]. Accordingly, turnover is a serious and increasing problem in call center and turnover rates in call center is extremely high which suggests call center as an ideal environment in which to study stress and burnout [7]. A study indicated that the factors of burnout like emotional exhaustion, depersonalization, and reduced personal accomplishment increased turnover intentions [8].

It is the goal of this research to describe and explore the phenomenon of burnout among call center agents using this instrument, the MBI-GS. The MBI-GS is the widely used and accepted measure of burnout. The burnout measure of the MBI-GS has been dominated by Western studies and they are insufficiently adapted to local circumstances. This paper also aimed to determine relationships among the demographic variables and the variables of the instrument since most studies do not systematically investigate demographic differences in burnout [9].

\section{Literature review}

Job burnout is commonly known as a three-dimensional, rather enduring syndrome of exhaustion, cynicism, and reduced professional efficacy that a person experience in relation to their work [10]. The first of these is exhaustion, is thought to be the most important, and is the first response to develop. It is characterized by extreme tiredness or a lack of energy and a feeling of being drained of emotional resources to cope with continuing demands [11, 12]. When people are experiencing burnout, they are most often referring to the experience of exhaustion because this is the most obvious manifestation of burnout. 
When employees reach this point of extreme tiredness, they act to conserve their levels of energy. To regulate their energy resources, they reduce their cognitive and emotional involvement with the work; in other words, they withdraw from their work. This leads to the second component of burnout, namely depersonalization or cynicism [13]. Cynicism is the cognitive dimension of burnout that refers to negative attitude toward one's work [9]; co-workers and the recipients of one's work that may be best described as dysfunctional disengagement and a gradual loss of concern. Outside of human services, people use cognitive distancing by developing a cynical attitude when they are discouraged or exhausted. Distancing is such an immediate reaction to exhaustion that a strong relation from exhaustion to depersonalization or cynicism is found consistently in burnout research, across a wide range of organization and occupational settings [10]. Depersonalization protects the employee from further emotional depletion that can serve as a coping response. This form of coping has serious implications for a company that makes use of service workers to provide their services because they tend to be less responsive to the needs of their customers $[13,4]$.

In the final phase of burnout - reduced personal accomplishment or low professional efficacy employees compare their current levels of competence with their previous levels of competence before emotional exhaustion and depersonalization had set in. In this self-evaluation, they see that they are not as competent and efficient as they used to be and feelings of incompetence, lack of achievement and lower productivity follow $[11,12]$.

\section{Statement of the problem}

The main purpose of this study was to determine the level of exhaustion, cynicism and professional efficacy of the call center employees.

Specifically, it sought to find answers to the following specific questions.

1. What are the level of burnout of the call center agents with the following dimensions:

1.1 Exhaustion

1.2 Cynicism

1.3 Professional Efficacy

2. What are the relationship between the levels of burnout and the profile of the respondents?

3. What are the differences in the level of burnout when grouped according to:

1.1 Gender

1.2 Age

1.3 Tenure at Present Job

1.4 Management Level

\section{Methodology}

The descriptive method of research was used in this study. The sample was gathered from sixteen call centers catering to local and international client companies. This study utilized convenience sampling involving the selection of the most accessible subjects [14]. A total of 747 call center agents participated in the study, of these, 338 are males $(45.20 \%)$ and 409 are females $(54.80 \%)$. Majority of the participants were between the ages of 18-29 years old (65.7\%). Two hundred and twenty or 29.5\% were tenured for 3-5 years, $219(29.3 \%)$ were working for 1-2 years and $171(22.9 \%)$ were working for 0-6 months in their present job. Majority of the call center agents were frontline staff comprising of 641 agents $(85.8 \%)$. Majority of the call center agents who participated were from Ortigas-Pasig City, the rest were from Pasay City, Makati City and some were from Cainta, Rizal. The call center agents should be working in the night shift to be included in this study.

The Maslach Burnout Inventory-General Survey (MBI-GS) was a self-report questionnaire that evaluates burnout among people in all occupations. The survey plus a demographic profile that includes information on gender, age, tenure at the present job and management level were distributed to call center agents in Metro Manila. The confidentiality and anonymity of the data was 
emphasized. Mean was used to categorize the level of exhaustion, cynicism and professional efficacy. Percentage was used to present the result of the level of exhaustion, cynicism and professional efficacy. Chi-square was used to compute for the relationship between age, tenure at present job and management level and exhaustion, cynicism and professional efficacy. T-test was utilized to check the differences between gender and the variables. One-Way ANOVA was used to check the differences of the exhaustion, cynicism and professional efficacy when grouped according to age, tenure at present job and management level.

\section{Results and Discussion}

Table 1. Exhaustion Level When Group According to Age, Gender, Tenure at Present Job and Management Level

\begin{tabular}{|c|c|c|c|c|c|c|c|c|}
\hline Age & Low & $\%$ & Average & $\%$ & High & $\%$ & Total & $\%$ \\
\hline $18-29$ & 161 & 21.6 & 126 & 16.9 & 204 & 27.3 & 491 & 65.7 \\
\hline $30-39$ & 98 & 13.1 & 48 & 6.4 & 80 & 10.7 & 226 & 30.3 \\
\hline $40-49$ & 15 & 2.0 & 4 & 0.5 & 4 & 0.5 & 23 & 3.1 \\
\hline $50-59$ & 3 & 0.4 & 1 & 0.1 & 3 & 0.4 & 7 & 0.9 \\
\hline Total & 277 & 37.1 & 179 & 24.0 & 291 & 39.0 & 747 & 100 \\
\hline \multicolumn{9}{|l|}{ Gender } \\
\hline Female & 152 & 20.3 & 101 & 13.5 & 156 & 20.9 & 409 & 54.8 \\
\hline Male & 125 & 16.7 & 78 & 10.4 & 135 & 18.1 & 338 & 45.2 \\
\hline Total & 277 & 37.1 & 179 & 24.0 & 291 & 39.0 & 747 & 100 \\
\hline \multicolumn{9}{|c|}{ Tenure at Present Job } \\
\hline $0-6$ months & 70 & 9.4 & 34 & 4.6 & 67 & 9.0 & 171 & 22.9 \\
\hline 7- 11 months & 41 & 5.5 & 19 & 2.5 & 33 & 4.4 & 93 & 12.4 \\
\hline $1-2$ years & 82 & 11.0 & 59 & 7.9 & 78 & 10.4 & 219 & 29.3 \\
\hline $3-5$ years & 71 & 9.5 & 61 & 8.2 & 88 & 11.8 & 220 & 29.5 \\
\hline $6-10$ years & 10 & 1.3 & 5 & 0.7 & 22 & 2.9 & 37 & 5.0 \\
\hline $11-15$ years & 3 & 0.4 & 1 & 0.1 & 3 & 0.4 & 7 & 0.9 \\
\hline Total & 277 & 37.1 & 179 & 24.0 & 291 & 39.0 & 747 & 100 \\
\hline \multicolumn{9}{|c|}{ Management Level } \\
\hline Frontline Staff & 247 & 33.1 & 154 & 20.6 & 240 & 32.1 & 641 & 85.8 \\
\hline $\begin{array}{l}\text { Management } \\
\text { (1st Level) }\end{array}$ & 15 & 2.0 & 7 & 0.9 & 30 & 4 & 52 & 7.0 \\
\hline $\begin{array}{l}\text { Management } \\
\text { (Intermediate) }\end{array}$ & 0 & 0.0 & 1 & 0.1 & 2 & 0.3 & 3 & 0.4 \\
\hline $\begin{array}{l}\text { Management } \\
\text { (Senior) }\end{array}$ & 0 & 0.0 & 1 & 0.1 & 4 & 0.5 & 5 & 0.7 \\
\hline Supervisor & 15 & 2.0 & 16 & 2.1 & 15 & 2 & 46 & 6.2 \\
\hline Total & 277 & 37.1 & 179 & 24.0 & 291 & 39.0 & 747 & 100 \\
\hline
\end{tabular}

Table 1 illustrates the frequency of the exhaustion level when grouped according to the demographic profiles. The age group of 18-29 experiences high exhaustion with 204 agents (27.3\%);156 females $(20.9 \%)$ reported to be exhausted than males (18.1\%).Among the agents those who worked for 3-5 years reported the most high in exhaustion with 88 agents $(11.8 \%)$. Though there are $240(32.1 \%)$ agents who are frontline staff who are high in exhaustion, there were 247 (33.1\%) who reported to have low exhaustion. The result of this table suggest that though there are more call center agents who reported high in exhaustion (39\%) there were also those who reported low in exhaustion (37.1\%). Those who reported low in exhaustion may be able to deal with their work effectively compared to the rest of the call center agents.

The call center agents are experiencing high exhaustion because part of their work have to deal with periods of uncontrollable high call traffic during which they need to face clients without a break or time out [11]. When grouped according to management level, there is almost an equal number of agents who are experiencing low exhaustion and high exhaustion. If we try to look at the tenure at 
present job, majority of highly exhausted agents came from the tenured agents, those who stayed in the company for 1-2 years and 3-5 years. A study of Dutch call center agents showed that employees in the different job positions differed regarding their demands and resources, their health problems and involvement, and regarding their absenteeism and turnover intentions. Teleconsultants reported the highest scores on repetitive strain injury (RSI) complaints, and they had been most often absent for longer time periods. [15] The result of this Dutch call center study is similar with the result of this present study as indicated in the table; the supervisors are also exhausted, most especially the front-line staff.

Emotional stress would seem to be a main type of stress in many call centers rather than physical stress. Training agents to deal with difficult customers, possible job redesign including escalating the difficult customers to those with more training and the ability to address their issues, and HR interventions to reduce employee stress are needed. If this is the case, those who may be experiencing the exhaustion part of the work are those who stayed in the company for a long time because they are the one's handling the escalation part of handling difficult customers because as supervisor they are more able to address this kind of issue. [7]

Table 2. Cynicism Level When Group According to Age, Gender and Tenure at Present Job and Management Level

\begin{tabular}{|c|c|c|c|c|c|c|c|c|}
\hline Age/Level & Low & $\%$ & Average & $\%$ & High & $\%$ & Total & $\%$ \\
\hline $18-29$ & 55 & 7.4 & 145 & 19.4 & 291 & 39.0 & 491 & 65.7 \\
\hline $30-39$ & 26 & 3.5 & 64 & 8.6 & 136 & 18.2 & 226 & 30.3 \\
\hline $40-49$ & 2 & 0.3 & 5 & 0.7 & 16 & 2.1 & 23 & 3.1 \\
\hline $50-59$ & 2 & 0.3 & 2 & 0.3 & 3 & 0.4 & 7 & 0.9 \\
\hline Total & 85 & 11.4 & 216 & 28.9 & 446 & 59.7 & 747 & 100.0 \\
\hline \multicolumn{9}{|l|}{ Gender } \\
\hline Female & 48 & 6.4 & 111 & 14.9 & 250 & 33.5 & 409 & 54.8 \\
\hline Male & 37 & 5.0 & 105 & 14.1 & 196 & 26.2 & 338 & 45.2 \\
\hline Total & 85 & 11.4 & 216 & 28.9 & 446 & 59.7 & 747 & 100.0 \\
\hline \multicolumn{9}{|c|}{ Tenure at Present Job } \\
\hline $0-6$ months & 23 & 3.1 & 47 & 6.3 & 101 & 13.5 & 171 & 22.9 \\
\hline 7- 11 months & 12 & 1.6 & 38 & 5.1 & 43 & 5.8 & 93 & 12.4 \\
\hline $1-2$ years & 21 & 2.8 & 64 & 8.6 & 134 & 17.9 & 219 & 29.3 \\
\hline $3-5$ years & 25 & 3.3 & 55 & 7.4 & 140 & 18.7 & 220 & 29.5 \\
\hline $6-10$ years & 3 & 0.4 & 11 & 1.5 & 23 & 3.1 & 37 & 5.0 \\
\hline $11-15$ years & 1 & 0.1 & 1 & 0.1 & 5 & 0.7 & 7 & 0.9 \\
\hline Total & 85 & 11.4 & 216 & 28.9 & 446 & 59.7 & 747 & 100 \\
\hline \multicolumn{9}{|c|}{ Management Level } \\
\hline Frontline Staff & 72 & 9.6 & 192 & 25.7 & 377 & 50.5 & 641 & 85.8 \\
\hline $\begin{array}{l}\text { Management } \\
\text { (1st Level) }\end{array}$ & 5 & 0.7 & 9 & 1.2 & 38 & 5.1 & 52 & 7.0 \\
\hline $\begin{array}{l}\text { Management } \\
\text { (Intermediate) }\end{array}$ & 0 & 0.0 & 1 & 0.1 & 2 & 0.3 & 3 & 0.4 \\
\hline $\begin{array}{l}\text { Management } \\
\text { (Senior) }\end{array}$ & 1 & 0.1 & 1 & 0.1 & 3 & 0.4 & 5 & 0.7 \\
\hline Supervisor & 7 & 0.9 & 13 & 1.7 & 26 & 3.5 & 46 & 6.2 \\
\hline Total & 85 & 11.4 & 216 & 28.9 & 446 & 59.7 & 747 & 100.0 \\
\hline
\end{tabular}

Table 2 presents the level of cynicism for the call center agents with an alarming $59.7 \%$ of the call center agents with high cynicism. More than half of the call center agents reported to be feeling indifferent or having a distant attitude toward their work. Majority were females $(33.5 \%)$, aged 18 $29(39 \%)$ and those who have worked for 3-5 years (18.7\%) and half are frontline staff $(50.5 \%)$. Because a majority reported to be exhausted some of the exhaustion may spill over to their work hence the feeling of being indifferent was reported. 
Emotional exhaustion, depersonalization, and reduced personal accomplishment increased turnover intentions. Emotional exhaustion led to a sharp increase in depersonalization, depersonalization is used as a term referring to cynicism in the first version of the Maslach scale [8]. A research studies showed that high scores on one dimension of burnout(i.e., either cynicism or exhaustion) were "early warnings" that those people were in a state of transition and change, but that if these people also showed mismatch scores ("tipping points") on at least one of the six areas, then their transition was to burnout[16]. It is very clear that due to the high scores in exhaustion from the previous table that there is also an elevated scores in cynicism.

Table 3. Professional Efficacy Level When Group According to Age, Gender, Tenure at Present Job and Management Level

\begin{tabular}{|c|c|c|c|c|c|c|c|c|}
\hline Age/Level & Low & $\%$ & Average & $\%$ & High & $\%$ & Total & $\%$ \\
\hline $18-29$ & 222 & 29.7 & 106 & 14.2 & 163 & 21.8 & 491 & 65.7 \\
\hline $30-39$ & 132 & 17.7 & 44 & 5.9 & 50 & 6.7 & 226 & 30.3 \\
\hline $40-49$ & 16 & 2.1 & 4 & 0.5 & 3 & 0.4 & 23 & 3.1 \\
\hline $50-59$ & 2 & 0.3 & 2 & 0.3 & 3 & 0.4 & 7 & 0.9 \\
\hline Total & 372 & 49.8 & 156 & 20.9 & 219 & 29.3 & 747 & 100 \\
\hline \multicolumn{9}{|l|}{ Gender } \\
\hline Female & 209 & 28.0 & 85 & 11.4 & 114 & 15.3 & 409 & 54.8 \\
\hline Male & 163 & 21.8 & 70 & 9.4 & 105 & 14.1 & 338 & 45.2 \\
\hline Total & 372 & 49.8 & 155 & 20.7 & 219 & 29.3 & 747 & 100.0 \\
\hline \multicolumn{9}{|c|}{ Tenure at Present Job } \\
\hline $0-6$ months & 82 & 11.0 & 35 & 4.7 & 54 & 7.2 & 171 & 22.9 \\
\hline 7-11 months & 51 & 6.8 & 19 & 2.5 & 23 & 3.1 & 93 & 12.4 \\
\hline $1-2$ years & 118 & 15.8 & 38 & 5.1 & 63 & 8.4 & 219 & 29.3 \\
\hline $3-5$ years & 106 & 14.2 & 51 & 6.8 & 63 & 8.4 & 220 & 29.5 \\
\hline $6-10$ years & 13 & 1.7 & 12 & 1.6 & 12 & 1.6 & 37 & 5.0 \\
\hline $11-15$ years & 2 & 0.3 & 1 & 0.1 & 4 & 0.5 & 7 & 0.9 \\
\hline Total & 372 & 49.8 & 156 & 20.9 & 219 & 29.3 & 747 & 100 \\
\hline \multicolumn{9}{|c|}{ Management Level } \\
\hline Frontline Staff & 333 & 44.6 & 133 & 17.8 & 175 & 23.4 & 641 & 85.8 \\
\hline $\begin{array}{l}\text { Management } \\
\text { (1st Level) }\end{array}$ & 19 & 2.5 & 14 & 1.9 & 19 & 2.5 & 52 & 7.0 \\
\hline $\begin{array}{l}\text { Management } \\
\text { (Intermediate) }\end{array}$ & 0 & 0.0 & 1 & 0.1 & 2 & 0.3 & 3 & 0.4 \\
\hline $\begin{array}{l}\text { Management } \\
\text { (Senior) }\end{array}$ & 1 & 0.1 & 1 & 0.1 & 3 & 0.4 & 5 & 0.7 \\
\hline Supervisor & 19 & 2.5 & 7 & 0.9 & 20 & 2.7 & 46 & 6.2 \\
\hline Total & 372 & 49.8 & 156 & 20.9 & 219 & 29.3 & 747 & 100.0 \\
\hline
\end{tabular}

Table 3 presents the level of professional efficacy with female (209) as experiencing low professional efficacy, those who are aged 18-29 (222), those who have worked for 1-2years (118) and frontline staffs (333). There are a total of $372(49.8 \%)$ call center agents experiencing low professional efficacy and $219(29.3 \%)$ as experiencing high professional efficacy. Though a majority are experiencing low professional efficacy, there are still a large number of call center agents who viewed themselves to be effective in their work. Monetary rewards reduced turnover intentions under depersonalization, whereas they increased turnover intentions under reduced personal accomplishment. Career paths reduced turnover intentions under both depersonalization and reduced personal accomplishment [8]. 
Table 4. Significant Relationship between exhaustion, cynicism and professional efficacy and the respondent's Profile

\begin{tabular}{|l|l|l|l|l|}
\hline Variable & Computed X $^{\mathbf{2}}$ & d.f. & $\boldsymbol{p}$-value & Interpretation \\
\hline Age and Level of Exhaustion & 16.15 & 6 & 0.013 & Significant \\
\hline Age and Level of Cynicism & 3.21 & 6 & 0.782 & Not Significant \\
\hline Age and Professional Efficacy & 17.57 & 6 & 0.007 & Significant \\
\hline Gender and Level of Exhaustion & 0.36 & 2 & 0.836 & Not Significant \\
\hline Gender and Level of Cynicism & 1.39 & 2 & 0.498 & Not Significant \\
\hline Gender and Professional Efficacy & 0.96 & 2 & 0.619 & Not Significant \\
\hline $\begin{array}{l}\text { Tenure at Present Job and Level of } \\
\text { Exhaustion }\end{array}$ & 15.11 & 10 & 0.128 & Not Significant \\
\hline $\begin{array}{l}\text { Tenure at Present Job and Level of } \\
\text { Cynicism }\end{array}$ & 11.95 & 10 & 0.289 & Not Significant \\
\hline $\begin{array}{l}\text { Tenure at Present Job and Professional } \\
\text { Efficacy }\end{array}$ & 11.06 & 10 & 0.353 & Not Significant \\
\hline $\begin{array}{l}\text { Management Level and Level of } \\
\text { Exhaustion }\end{array}$ & 17.61 & 8 & 0.024 & Significant \\
\hline Management Level and Level of Cynicism & 5.99 & 8 & 0.648 & Not Significant \\
\hline $\begin{array}{l}\text { Management Level and Professional } \\
\text { Efficacy }\end{array}$ & 15.32 & 8 & 0.053 & Not Significant \\
\hline
\end{tabular}

$\alpha=0.05^{*}$.

Table 4 presents the chi-square results of the relationship between the level of exhaustion, cynicism and professional efficacy with the respondent's profile. There is a significant relationship between age and level of exhaustion with a p-value of 0.013, age and professional efficacy with a p-value of 0.007 and management level and exhaustion with a p-value of 0.024 , the result is significant at the 0.05 alpha level. Age may have an influence with how the call center agents experience exhaustion and cynicism. Those who are aged 18-29 reported to have an increase in exhaustion and professional efficacy since majority of them are new in their work (frontline staff) therefore are in the adjustment period. Age also has something to do with the multiple roles of the call center agents being a breadwinner, interest in relationships, conformity with peer groups etc. No reported significant differences was reported in the area of cynicism since the result suggest that almost all of the call center agents reported a high in cynicism. Burnout is prevalent in young workers in the United States who are aged under 30 with little or no work experience. [10]

Results from the study showed that young workers are more concerned about growing in their profession and contributing to their family. They are motivated by a personal sense of accomplishment and do what they love or enjoy[14] Young workers including the call center agents' place a great value on family and work is seen as a reason to provide, to help or support their family. Those who are new in the call center industry may be the newly graduates who are supporting their family and these agents take pride in providing support for their parents or sending their siblings to college.

Table 5. T -test Between Exhaustion, Cynicism and Professional Efficacy and Gender

\begin{tabular}{|l|l|l|l|}
\hline Variables & t- value & $\boldsymbol{p}$ value & Interpretation \\
\hline Exhaustion & -0.90 & 0.370 & Not Significant \\
\hline Cynicism & -0.62 & 0.537 & Not Significant \\
\hline Professional Efficacy & -0.25 & 0.801 & Not Significant \\
\hline
\end{tabular}

$*$ d.f. $=745, \alpha=0.05$

Table 5 presents the result of t-test between the burnout level and gender, suggests that the differences in the exhaustion, cynicism and professional efficacy scores does not differ whether they are males or females. Women have less access to job related rewards such as high income, social status and autonomy because they occupy non-supervisory roles in organization compared to men. When these confounding variables are considered, no significant gender differences in burnout 
are observed, except for depersonalization [17]. It is consistently found that males report higher depersonalization scores than females, because males have higher prevalence of aggression while females have higher interest in the nurturing role [12]. The result of this study is similar with the result of previous study except for the higher depersonalization in males, the gender differences could not account for this differences since all reported to be high in depersonalization.

Table 6. Analysis of Variance between Exhaustion, Cynicism and Professional Efficacy and Age

\begin{tabular}{|l|l|l|l|}
\hline Variables & F & $\boldsymbol{p}$ value & Interpretation \\
\hline Exhaustion & 3.50 & 0.015 & Significant \\
\hline Cynicism & 0.29 & 0.834 & Not Significant \\
\hline Professional Efficacy & 14.56 & 0.000 & Significant \\
\hline
\end{tabular}

$*$ d.f $=3,743, \alpha=0.05$

Table 6 shows that exhaustion variable with a $p$ value of 0.015 and professional efficacy with a $p$ value of 0.000 is significant at 0.05 level when grouped according to age. This suggest that one of the age group has significantly higher score. The age group of 18-29 has higher scores on these two variables since the majority of the call center agents are from this age group.

Burnout has been reported in occupations occurring among health care workers, teachers and social workers. There are not substantial differences in burnout levels associated with gender, race or age [13]. Burnout does changes with work conditions that may in turn related to demographic characteristics. Many organizations, women have lower status positions relative to men, and the female workers may also report more indicators of burnout due to diminished quality of their worklife. Customer service representatives are expected to avoid showing any form of negative emotion towards customers and to remain friendly and polite in spite of how they really feel. Emotional dissonance therefore seems to be higher in call centers.[18] Emotional dissonance is the most stressful aspect of emotional work and that emotional exhaustion is predicted via emotional dissonance [19].

Table 7. Analysis of Variance Between Exhaustion, Cynicism and Professional Efficacy and Tenure at Present Job

\begin{tabular}{|l|l|l|l|}
\hline Variables & F & $\boldsymbol{p}$ value & Interpretation \\
\hline Exhaustion & 0.86 & 0.508 & Not Significant \\
\hline Cynicism & 0.68 & 0.640 & Not Significant \\
\hline Professional Efficacy & 2.63 & 0.023 & Significant \\
\hline
\end{tabular}

$*$ d.f $=5,741, \alpha=0.05$

Table 7 shows that the $p$ value of 0.023 for the variable professional efficacy is significant at 0.05 level when grouped according to tenure at present job. This suggests that one of the group differ significantly in their scores in professional efficacy. Fifteen percent of the call center agents who have worked for 1-2 years reported to be low in professional efficacy, this tenure got the highest frequency compared to the rest of the group. This can be explained that those staying for 1 to 2 years may already feel incompetent and insufficient with their work and instead of resigning from their job, they decided to stay and continue with their work. There are "survivors" who are the remaining group of more experienced employees, especially older one who did experienced burnout but did not quit their job [20].

Table 8. Analysis of Variance Between Exhaustion, Cynicism and Professional Efficacy and Management Level

\begin{tabular}{|l|l|l|l|}
\hline Variables & F & $\boldsymbol{p}$ value & Interpretation \\
\hline Exhaustion & 0.60 & 0.660 & Not Significant \\
\hline Cynicism & 0.40 & 0.811 & Not Significant \\
\hline Professional Efficacy & 1.78 & 0.131 & Not Significant \\
\hline
\end{tabular}


Table 8 revealed the $p$ value score of 0.0660 for exhaustion, 0.811 for cynicism and 0.131 for professional efficacy and these value is not significant at 0.05 level. This implies that management level does not differ in their perception of burnout. Since majority of the respondents are frontline staff and there are less representation of the other management level, no significance emerged.

\section{Conclusion}

The study concludes that majority of the call center respondents are highly exhausted, highly cynical and experiencing low professional efficacy. The high level of emotional exhaustion lead to a sharp increase in cynicism and an experience of low professional efficacy. Those who are relatively young compared to the other age group are experiencing exhaustion which could be due to their lack of experience in handling excessive job demand or coping with difficult or irate customers. The agents may have the technical training in computers and technologies but the soft skills like handling emotional stress may be lacking. When these agents feel they cannot handle the task, the feelings of incompetence, lack of achievement and lower productivity may be reported hence their score in low professional efficacy.

\section{References}

[1] R. Periabras, The new call center capital of the world. The Manila Times. Retrieved from http://www.manilatimes.net/philippines-the-new-call-center-capital-of-the-world/47984/, 2013.

[2] L. Holdsworth, S. Cartwright, Empowerment, stress and satisfaction: An exploratory study of a call centre, Leadership and Organization Development Journal, 24:3 (2003) 131-140.

[3] N. Malhotra, A. Mukherjee, The relative influence of organizational commitment and job satisfaction on service quality of customer-contact employees in banking call centers, Journal of Services Marketing, 18:3 (2004) 162-174.

[4] J. Singh, J.R. Goolsby, Behavioral and psychological consequences of boundary-spanning burnout for customer service representatives, Journal of Marketing Research, 94 (1994) 558570.

[5] W.A. Visser, S. Rothmann, Exploring antecedents and consequences of burnout in a call centre: empirical research, SA Journal of Industrial Psychology, 34:2 (2008) 79-87.

[6] R.M. Hechanova, The call center as a revolving door: a Philippine perspective, Personnel Review, 42:3 (2013) 349-365

[7] P.C. Ruppel, R. Sims, P. Zeidler, Emotional labour and its outcomes: a study of a Philippine call centre, Asia-Pacific Journal of Business Administration, 5:3 (2013) 246-261.

[8] S. Choi, K. Cheong, R.A. Feinberg, Moderating effects of supervisor support, monetary rewards, and career paths on the relationship between job burnout and turnover intentions in the context of call centers, Managing Service Quality: An International Journal, 22:5 (2012) 492516.

[9] W.B. Schaufeli, B.P Buunk, Burnout: An overview of 25 years of research and theorizing. The handbook of work and health psychology, 2 (2003) 282-424.

[10] W.B. Schaufeli, M.P.Leiter, C. Maslach, S.E. Jackson, The Maslach Burnout InventoryGeneral Survey, in C. Maslach, S.E. Jackson, \& M.P. Leiter (Eds.), Maslach Burnout Inventory. Palo Alto, CA: Consulting Psychologists Press, 1996.

[11] C.L. Cordes, T.W. Dougherty, A review and an integration of research on job burnout. Academy of Management Review, 18:4 (1993) 621-656.

[12] E.D. Ogus, E.R. Greenglass, R.J.Burke, Gender-role differences, work stress and depersonalization, Journal of Social Behavior and Personality, 5 (1990) 387-398.

[13] C. Maslach, W.B. Schaufeli, M.P. Leiter, Job burnout, Annual review of psychology, 52:1 (2001) 397-422.

[14] M. N. Marshall, Sampling for qualitative research, Family practice, 13:6 (1996) 522-526. 
[15] A. Bakker, E. Demerouti, W. Schaufeli, Dual processes at work in a call centre: An application of the job demands-resources model, European journal of work and organizational psychology, 12:4 (2003) 393-417.

[16] C. Maslach, M.P. Leiter, Early predictors of job burnout and engagement, Journal of Applied Psychology, 93 (2008) 498-512.

[17] E. Greenglass, Burnout and gender: theoretical and organizational implications, Canadian Psychology, 32 (1991) 562-574.

[18] P.F. Zapf, A. Isic, M. Bechtoldt, P. Blau, What is typical for call centre jobs? Job characteristics and service interactions in different call centres, European Journal of Work and Organizational Psychology, 12:4 (2003) 311-340.

[19] K.A. Lewig, M.F. Dollard, Emotional dissonance, emotional exhaustion and job satisfaction in call centre workers, European Journal of Work and Organizational Psychology, 12:4 (2003) 366-392.

[20] R.A. Karasek, T Theorell, Healthy Work: Stress, Productivity and the Reconstruction of Working Life. Basic Books, New York, 1990. 